\title{
STUDY ON EVALUATION OF ANTIDEPRESSANT EFFECT OF CYMBOPOGON CITRATUS (LEMON GRASS) IN ALBINO MICE
}

\begin{tabular}{ll}
\hline Pharmacology & \\
$\begin{array}{ll}\text { Dr. R. Mangala } \\
\text { Devi }\end{array}$ & M.D Assistant Professor, Institute of Pharmacology, Madurai Medical College \\
\hline Dr. R. Sarojini* & $\begin{array}{l}\text { M.D Professor, Institute of Pharmacology, Madurai Medical College. }{ }^{*} \text { Corresponding } \\
\text { Author }\end{array}$ \\
\hline Dr. S. Vasanth & $\begin{array}{l}\text { M.D DNB Assistant Professor, Department Of Pharmacology, Government Sivagangai } \\
\text { Medical College }\end{array}$ \\
\hline
\end{tabular}

ABSTRACT

BACKGROUND: Depression is a common psychiatric disorder. Drug therapy is the cornerstone in the management of depression. Antidepressants are associated with many unwanted side-effects. Thus, various herbal products have been tried. The advantages of herbal treatments include safety, cheap and acceptability due to their traditional values. The objective of the present study was to evaluate the anti-depressant activity of Cymbopogon citratus (lemon grass) in albino mice and to compare with Imipramine. Methods: 30 Swiss albino male mice weighing around 25$30 \mathrm{~g}$ were divided into 5 groups $(\mathrm{n}=6)$. Group I (Control) mice were given normal feed and water, Group II (Standard) received $20 \mathrm{mg} / \mathrm{kg} \mathrm{T}$. Imipramine orally, Group III (Test-1) received $5 \mathrm{mg} / \mathrm{kg}$ aqueous extract of C. citratus (lemon grass) orally and Group IV (Test-2) received $10 \mathrm{mg} / \mathrm{kg}$ C. citratus (lemon grass) orally, and Group V (Test-3) received both T. Imipramine (10 mg/kg) and C. citratus (10 mg/kg) orally. Duration of immobility was observed for last 4 mins of total 6 mins period in groups 1-5 by tail suspension test on 1st, 8th and 15th day.Results: Duration of immobility recorded in seconds was analyzed by one-way analysis of variance, followed by Tukey's post-hoc test Conclusion: Lemon grass has a significant antidepressant effect. Combined effect of lemon grass at $10 \mathrm{mg} / \mathrm{kg}$ and imipramine $10 \mathrm{mg} / \mathrm{kg}$ is not synergistic.

\section{KEYWORDS}

Anti Depressant Effect, Lemon Grass, Tail Suspension Test, Immobility

\section{INTRODUCTION :}

Depression is a common psychiatric disorder, associated with poor concentration, lack of interest, loss of pleasure, guilt, altered sleep and appetite. There is also an increased suicidal tendency. The outlook of management of depression was gloomy previously. Most of the psychiatric problems were treated in asylum. Now with a better understanding of etiopathogenesis of the disease, with advent of new drugs and other treatment modalities for depression, it is possible to treat the disease at primary health care set up. The cornerstone in the management of depression is by drugs. By combining non pharmacological therapy like Cognitive Behavioral Therapy (CBT) and interpersonal therapy it is almost curable.Pharmacotherapy is the most effective intervention in the management of Major Depressive Disorder (MDD). It helps to achieve remission and also prevents relapse. Among the drugs available Selective Serotonin Reuptake Inhibitors (SSRIs) and Serotonin Noradrenalin Reuptake Inhibitors (SNRIs) are the most commonly used drugs. They belong to second generation antidepressant drugs. Tricyclic Antidepressants (TCAs) and Monoamine Oxidase Inhibitors (MAOIs) are referred to as first generation drugs but currently not preferred because of lack of selective targeting and an array of adverse effects like cardiac conduction abnormalities. The drugs employed in the management of MDD either decrease the degradation or block the reuptake of noradrenaline and serotonin at the synapse. Among the many newer antidepressants available, SSRIs are claimed to be safe with better tolerability profile but they too have adverse effects. Noncompliance is approximately $40 \%$ in patients seeking primary care, receiving drug therapy alone because of delayed onset of therapeutic effects unless otherwise supported by other modalities like cognitive behavioral therapy (CBT). In a good compliant patient too, who is adequately managed with drugs alone, remission is only in 60-70\%. However, no drug is free from side effects. As all classes of anti depressants have almost similar efficacy, it is the unwanted adverse effects which are important in choosing a drug for a particular individual. Hence, the hunt for newer drugs in the management of depression is an ongoing topic of research. An ideal drug exhibiting better safety and tolerability, which cures depression most efficiently is sought for. In order to bridge the defects in the modern medical system, complementary and alternative medicine helps. Natural products from plants have played an important role in the lives of human beings from time immemorial. It is a belief that traditional medicine lack efficacy and evidence and are inferior to allopathic medicine. However, it is not so. Traditional medicine helps in conditions like sleep disorders, cardiovascular disorders, chronic pain, depression, obesity, erectile dysfunction, common cold, etc., Many effective drugs have come from a wide armamentarium of herbs. Cymbopogon citratus, which is known by its common name as lemon grass is often used as a flavouring agent in cooking and in aroma therapy. This plant has also got a wide range of medicinal properties and it is in use as a folk remedy in many parts of the world. Since an ideal antidepressant is still awaited, and it is always an area of research, lemon grass, a common culinary herb having antidepressant property is selected for this study Screening methods for evaluation of antidepressant property are always difficult because of lack of a typical animal model. Of the many in vivo animal models available, we planned to study the antidepressant activity of lemon grass in Swiss albino mice by tail suspension method.

\section{AIM:}

To evaluate of antidepressant effect of Cymbopogon citratus (Lemon Grass) in albino mice by tail suspension test.

\section{METHODS \& MATERIALS}

In the present study, the antidepressant activity of lemon grass was evaluated in Swiss albino mice by tail suspension test. Approval was obtained from Institutional Animal Ethical Committee of Madurai Medical College, Madurai, before commencing the experiment. (R.No:5953/E1/5/2015)

NUMBER OF ANIMALS USED:30 adult male albino mice weighing about $25-30$ grams

\section{DRUGSAND CHEMICALS REQUIRED}

Standard drug - Tab. Imipramine $5 \mathrm{mg} / \mathrm{kg}$ (oral)

Test drug - Aqueous extract of Cymbopogon citratus (Lemon Grass) (oral) Distilled water

\section{INSTRUMENTS REQUIRED:}

Adhesive tapes

Table with a bar for suspension

Plastic tubes $4 \mathrm{cms} \times 1.5 \mathrm{cms}$

Digital camera with tripod stand

Stirrers and beakers

Electronic balance

Syringes

Oral feeding tube

Stop watch

\section{LEMON GRASS EXTRACT PREPARATION:}

The plant was obtained from hilly areas of Courtallam and the species was identified and authenticated by Dr. Stephen, taxonomist, of 
American College, Madurai and further processing was done by Pharmacognosy department, of Madurai Medical College. $100 \mathrm{~g}$ of fresh leaves was extracted with distilled water for 24 hours and filtered with sterile Whatman's number 1 filter paper. The filtrate obtained was concentrated under reduced pressure using rotavapour (Buchi model). The green colour residue obtained was stored in refrigerator at $4^{\circ} \mathrm{C}$ until required. The extract was weighed and reconstituted daily, with distilled water according to the dosage needed $(5 \mathrm{mg} / \mathrm{kg} \mathrm{\&} 10 \mathrm{mg} / \mathrm{kg})$ and administered orally, for a period of 15 days.

\section{IMIPRAMINE HYDROCHLORIDE:}

Imipramine hydrochloride tablets purchased from Sun Pharma were used as a standard drug in the dose of $10 \mathrm{mg} / \mathrm{kg} \& 20 \mathrm{mg} / \mathrm{kg}$, dissolved with distilled water and administered by the oral route.

\section{PROCEDURE:}

The animals were selected from Central Animal House, Madurai Medical College, Madurai. The animals were housed in polypropylene cage at room temperature with a 12 hours: 12 hours light / dark cycle. They had free access to food and water ad libitum. They were acclimatized to laboratory conditions for at least 1 week before starting the study. The study followed the principles of CPCSEA and utmost care was taken while handling the animals and adequate care was provided to them during and after experimentation. The animals were divided into 5 groups of 6 animals in each group. Group I served as control, group II as standard and groups III, IV and V served as test groups respectively. Drugs were administered orally, using oral feeding tube fit on a $1 \mathrm{ml}$ syringe, once daily in the morning, for a period of 15 days, according to the groups as per the table below.

Table 1:Details of drug administration

\begin{tabular}{|l|l|l|}
\hline GROUP & STUDY & TREATMENT \\
\hline I & CONTROL & Normal feed + Water \\
\hline II & STANDARD & $\begin{array}{l}\text { Normal feed + Water + Tab. Imipramine } \\
20 \mathrm{mg} / \mathrm{kg} \text { orally }\end{array}$ \\
\hline III & TEST - 1 & $\begin{array}{l}\text { Normal feed + Water + Aqueous extract } \\
\text { of C. citratus } 5 \mathrm{mg} / \mathrm{kg} \text { orally }\end{array}$ \\
\hline IV & TEST - 2 & $\begin{array}{l}\text { Normal feed + Water +Aqueous extract } \\
\text { of C. citratus } 10 \mathrm{mg} / \mathrm{kg} \text { orally }\end{array}$ \\
\hline V & TEST - 3 & $\begin{array}{l}\text { Normal feed + Water + Aqueous extract } \\
\text { of C. citratus } 10 \mathrm{mg} / \mathrm{kg}+\text { Tab. Imipramine } \\
10 \mathrm{mg} / \mathrm{kg} \text { orally }\end{array}$ \\
\hline
\end{tabular}

$18-20 \mathrm{G}$ hypodermic needle which is blunted at the tip with a small ball soldered around the tip was used. The needle was attached to $1 \mathrm{ml}$ syringe containing the drug to be administered. Each mouse was grasped gently and secured by the nape of the neck, holding the whole animal with the left hand. After introducing the oral feeding tube laterally through the interdental space, it was advanced into the oesophagus with a gentle rotatory movement. Once it reached the desired level the drug was gently pushed inside.

\section{TAILSUSPENSION TEST:}

On day 1 , day 8 and day 15 , tail suspension test was carried out for the control, standard, test-1, test-2 and test-3 groups, one by one, group wise. After one hour of drug administration, tail suspension test was done, for all the 6 animals belonging to each group, at a time.

Prior to tail suspension, the camera was set in position in order to obtain the highest possible resolution of the animals. Plastic tubes, which act as climb stoppers, were introduced to the tail, prior to application of adhesive tapes. Tapes were applied to the tail tips leaving the last 2-3 $\mathrm{mm}$ free. Application of tapes was done gently to prevent apprehension and stress in animals even before suspension itself.

Then the mice were suspended one by one, by attaching the free end of the tape to the wooden bar, of a table with three walled rectangular chamber of dimensions, height $55 \mathrm{~cm} \times$ breath $20 \mathrm{~cm} \times$ depth $12 \mathrm{~cm}$. The compartments were adequately sized to prevent mouse getting in contact with the walls and the distance between the tips of the nose to the table was approximately $20 \mathrm{~cm}$.

The camera was set in such a way that the view was not obscured. The entire tail suspension time (TST) for the first 6 minutes was recorded without any interruption. At the end of 6 minutes the mice were placed back into the home cage after removing the tapes gently from their tails.
TAILSUSPENSION TEST - BEHAVIORALANALYSIS:

Tail suspension time was the first 6 minutes of hanging. The behavioral assessment of all the animals was done from the video recordings. Each animal was totally observed for 6 minutes. In this, the first 2 minutes were left for the animal to acclimatize and the behavioral assessment was done for the next 4 minutes.

During the behavioral assessment, the time that each mouse spent as immobile was noted, using a stop watch. The most important aspect of TST is the consistent differentiation between mobility and immobility. Escape related behaviors like movement of four limbs, shaking the body, running like limb movements, trying to touch the side walls were considered as mobility whereas small movements of the forelimbs alone without involvement of hind limbs and pendulum like movement of the tape due to momentum gained by the previous mobility were taken as immobility only. For each mouse, the immobility period was noted and the findings were tabulated. The immobility period recorded by doing tail suspension test in mice, after administration of test and standard drugs were subjected to statistical analysis.

\section{STASTICALMETHODS APPLIED}

\section{ONE - WAY ANOVA-ANALYSIS OF VARIANCE}

The One - way ANOVA procedure produces a one - way analysis of variance for a quantitative dependent variable by a single factor (independent) variable. Analysis of variance is used to test the hypothesis that several means are equal. This technique is an extension of the two-sample t test.

\section{POST HOC TEST - TUKEY'S POST HOC TEST}

Once it is determined that differences exist among the means, post hoc range test and pair wise multiple comparisons can determine which means differ. Range tests identify homogenous subsets of means that are not different from each other. Pair wise multiple comparisons test the difference between each pair of means, and yield a matrix.

\section{RESULTS:}

Control group mice were treated with normal feed and water and tail suspension test was done one hour after oral treatment on day 1, day 8 , day 15 and the immobility time was observed. The mean immobility period was calculated for the control group and expressed as mean \pm S.D.The mean immobility period for day 1 was $196 \pm 5.71$, on day 8 mean immobility period was $193 \pm 12$ and on day 15 mean immobility period was $199.5 \pm 2.4$. Standard group mice were treated with Tab. Imipramine $20 \mathrm{mg} / \mathrm{kg}$ orally and 1 hour after that tail suspension test was done on day 1 , day 8 , day 15 and the period of immobility was observed. The mean immobility period for the standard group was calculated and expressed as Mean \pm S.D. The mean immobility period for day 1 was found to be $207 \pm 2.88$, on day 8 mean immobility period was $167 \pm 3.1$ and on day 15 mean immobility period was $149.3 \pm$ 2.4.The mice in test group - I were treated with aqueous extract of lemon grass $5 \mathrm{mg} / \mathrm{kg}$ orally and 1 hour after that the tail suspension test was performed on day 1 , day 8 , day 15 and the period of immobility was observed. The mean immobility period for the test group I was calculated and expressed as Mean \pm S.D. The mean immobility period for day 1 was found to be $210 \pm 2.31$, and on day 8 the mean immobility period was $182 \pm 3.2$ while on day 15 the mean immobility period was found to be $162 \pm 3.0$. The calculated mean immobility period was subjected to one way analysis of variance. Analysis of variance is used to treat the test hypothesis that several means are equal. This technique is an extension of the two-sample t test.

Table 2:Mean immobility period in seconds on day 1, day 8, day 15 in all groups

\begin{tabular}{|l|l|l|l|l|l|}
\hline DAY & CONTROL & STANDARD & TESTI & TEST II & TEST III \\
\hline Day 1 & $196 \pm 5.71$ & $207 \pm 2.88^{* *}$ & $210 \pm$ & $199 \pm$ & $202 \pm$ \\
& & & $2.31^{* *}$ & $2.31^{*}$ & $2.16^{*}$ \\
\hline Day 8 & $193 \pm 1.2$ & $167 \pm 3.1^{* *}$ & $182 \pm$ & $171 \pm$ & $181 \pm$ \\
& & & $3.2^{*}$ & $2.6^{* *}$ & $3.8^{*}$ \\
\hline Day & $199.5 \pm 2.4$ & $149.3 \pm 2.4^{* *}$ & $162 \pm$ & $147.5 \pm$ & $160 \pm$ \\
15 & & & $3.0^{* *}$ & $3.2^{* *}$ & $2.3^{* *}$ \\
\hline
\end{tabular}

Not significant: $\mathrm{p}>0.05$; Significant: $\mathrm{p} \leq 0.05^{*} ;$ Highly significant: $\mathrm{p} \leq$ 0.01

\section{RESULTS OF ONE WAY ANOVA:}

When the results of day 1,8 and 15 were analyzed by one way anova, $F$ value is significant $(<0.05)$ for the degree of freedom. So the difference 
in the mean immobility time between groups is significant.

\section{POST HOC ANALYSIS}

The results were analyzed with post hoc-Tukey's test which showed a significant difference in the immobility period in the standard, test-1, test- 2 , test- 3 groups on day- 1 , day- 8 and day- 15 when compared to control. In some instances it was highly significant.

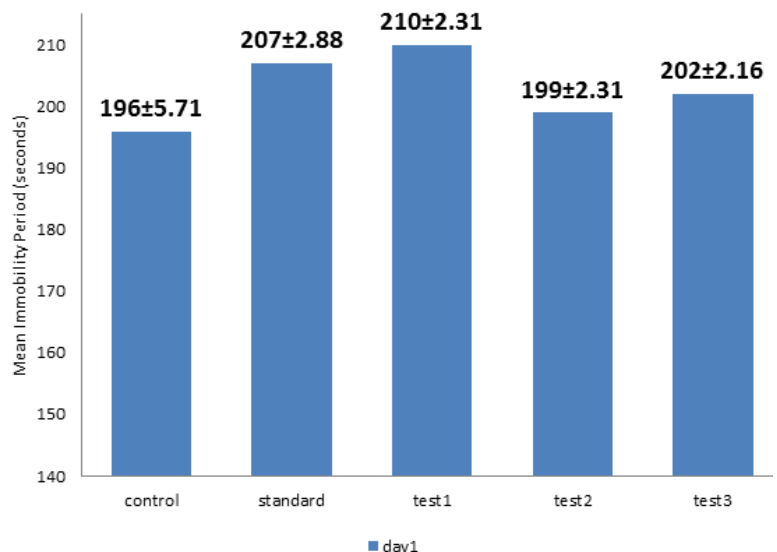

Figure 1: The mean immobility period in seconds on day 1 in all groups

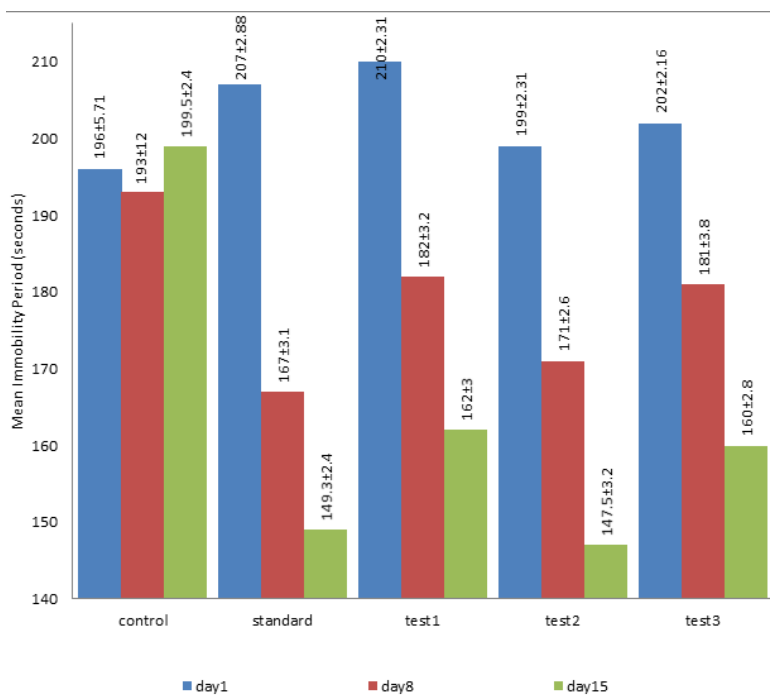

Figure 2: The mean immobility period in seconds on day 1 , day 8 , day 15 in all groups

\section{DISCUSSION \& CONCLUSION :}

Depression is a common psychiatric disorder, leading to major cause of disease burden all over the world. It is steadily increasing in the recent past. It is a mood disorder presenting with sadness, loss of pleasure, lack of interest almost all days for at least two weeks. It aggravates the underlying medical problems and worsens their prognosis. It is potentially fatal since $50 \%$ patients try to commit and $15 \%$ die due to suicide. Among the behavioral models available, Forced Swim Test (FST) and Tail Suspension Test (TST) are widely adopted animal models for evaluating the antidepressant effect. Tail suspension test is based on the innate behavior, with a greater sensitivity and high predictability. TST is easy to perform and well suited for high throughput screening of new compounds. In this study, antidepressant effect of aqueous extract of lemon grass was assessed using tail suspension test by observing the immobility period. On day 1 , it showed a significant increase in immobility period, in the standard and test groups when compared to control group. So it is evident that both drugs, imipramine and lemon grass extract, did not produce the desirable effect and the mechanism of which could not be explained. On day 8 , there was a highly significant decrease in immobility period in the standard group $(\mathrm{p} \leq 0.01)$ and a significant decrease in immobility period in the test groups $(\mathrm{p} \leq 0.05)$ when compared to control group. Additionally there was also a dose related effect in response with the test group. Lemon grass extract at a dose of $10 \mathrm{mg} / \mathrm{kg}$ administered, showed a greater decrease in immobility period compared to a dose of
$5 \mathrm{mg} / \mathrm{kg}$.On day 15 , there was a highly significant decrease in immobility period in the standard group and all the test groups $(\mathrm{p} \leq 0.01)$. It could be inferred that after continuous administration for 15 days, lemon grass extract at a dose of $10 \mathrm{mg} / \mathrm{kg}$ was more effective than the standard drug imipramine.But when we analyze the results produced by co-administration of lemon grass extract at a dose of 10 $\mathrm{mg} / \mathrm{kg}$ and imipramine at a dose of $10 \mathrm{mg} / \mathrm{kg}$, it was found that lemon grass didn't produce synergistic effect with imipramine. It could be possible that imipramine might have saturated the site of action of lemon grass. So there is a reduction in the response of lemon grass extract at a dose of $10 \mathrm{mg} / \mathrm{kg}$ when combined with imipramine. This was almost similar to that of lemon grass extract at a dose of $5 \mathrm{mg} / \mathrm{kg}$. It could be possible that lemon grass would have been acting as a partial agonist at the site of action of imipramine when given alone and oppose the effect of full agonist or it may be concluded that both lemon grass and imipramine compete for the same uptake mechanisms. In a previous study done by Dudhgaonkaret al, both tail suspension test and forced swim test were done after administration of lemon grass in graded doses and also along with imipramine. Imipramine was the standard drug. In their study also aqueous extract of lemon grass at a dose of $10 \mathrm{mg} / \mathrm{kg}$ showed maximum response (maximum reduction in immobility time). The effect of imipramine with lemon grass was less compared to lemon grass at a dose of $10 \mathrm{mg} / \mathrm{kg}$. It is postulated that depression is caused by impairment of monoaminergic transmission. Imipramine, which is a tricyclic antidepressant is an effective antidepressant by blocking the reuptake of noradrenaline and serotonin thereby enhancing monoaminergic neurotransmission in both adrenergic and serotonergic neurons. So, decrease in immobility time observed after administering lemon grass would have been due to an enhancement of monoaminergic transmission similar to that of imipramine. So it could be possible that by various mechanisms, like monoamine transmission enhancement similar to imipramine, antioxidant effect and anti-inflammatory effect due to the presence of flavanoids and phenols, aqueous extract of lemon grass has antidepressant property which is showed by reduction in the immobility time in tail suspension test.It was observed that Cymbopogon citratus (lemon grass) at low dose $(5 \mathrm{mg} / \mathrm{kg})$ showed significant antidepressant effect on $15^{\text {th }}$ day and at high dose (10 $\mathrm{mg} / \mathrm{kg}$ ), showed significant antidepressant effect on $8^{\text {th }}$ day itself which was comparable to that of imipramine. Combined effect of lemon grass at $10 \mathrm{mg} / \mathrm{kg}$ and imipramine $10 \mathrm{mg} / \mathrm{kg}$ is not synergistic. The study objective has been achieved. Further studies need to be done with more number of animals and different experimental models, to know the exact molecular and biological mechanism behind Cymbopogon citratus as an anti depressant. Identification and separation of the active principle that is responsible for the antidepressant effect has to be further evaluated. That will help the society in the near future.

\section{REFERENCES}

Sandeep Grover, Alakananda Dutt, and Ajit Avasthi. An overview of Indian research in Depression. Indian J Psychiatry. 2010 January; 52(Suppl1): S178-S188.

2. Benjamin J. Sadock, Virginia A. Sadock, Mood disorders. In: Pocket Hand book of Clinical Psychiatry. 5th Edition. Philadelphia; Lippincott Williams \& Wilkins; 2010. p. $175-200$

3. James M. O' Donnel and Richard C. Shelton. Drug Therapy of Depression and Anxiety Disorder. In: Laurence L. Brunton, Bruce A. Chabner, Bjorn C. Knollmann(eds.) Goodman \& Gilman's The pharmacological basis of therapeutics, 12th edition. New York: McGraw Hill; 2011: p 404-405.

4. Victor I Reus. Mental disorder In: Dan L Longo, Dennis L Kasper Larry Jameson.J, Antony S. Fauci, Stephen L. Hauser, Joseph Loscalso(eds.) Harrison's principles of Antony S. Fauci, Stephen L. Hauser, Joseph Loscalso(eds.) Harrison's prin
internal medicine, 18th edition. New York: McGraw Hill; 2012. p. 3535-3538.

5. Jerome Sarris; Herbal Medicines in the Treatment of Psychiatric Disorders: A Systematic Review. Phytotherapy Research. Aug 2007; Volume 21, Issue 8: 703-716.

6. Gagan Shah, Richa Shri, Vivek Panchal, Narendra Sharma, Bharpur Singh, A. S. Mann Scientific basis for the therapeutic use of Cymbopogon citratus, Stapf (Lemon grass) Journal of Advanced Pharmaceutical Technology \& Research. 2011 Jan-Mar; 2(1): 3-8 Sadock, Benjamin James; Sadock, Virginia Alcott: Depression and Bipolar Disorder In: Kaplan \& Sadock's Synopsis of Psychiatry: Behavioral Sciences/Clinical Psychiatry, Kaplan \& Sadock's Synopsis of Psychiatry: Behavioral Sciences/Clinical P
10th Edition. Philadelphia: Lippincott Williams \& Wilkins;2007. p. 527-562

8. Jerald Kay, Allan Tasman. Mood disorder: Depression. In: Essentials of Psychiatry. England: John Wiley and sons, 2006. p. 533-551.

9. Patrick R. Finley and Kelly C. Lee. Mood disorders I: Major Depressive Disorders. In Brian K. Alldredge, RobinL. Coreli, Michel E. Ernst, B. Joseph Gugliemo, Pamala A. Jacobson, Wayne A. Kradjan, Bradly R. Williams(eds.) Koda kimble \& Young's Applied Therapeutics The Clinical Use of Drugs,10thEdition. Philadelphia: Wolters Kluwer/ Lippin cott Williams and Wilkin; 2013.p.1949-1982.

10. Reddy MS. Depression: The disorder and burden. Indian journal of psychological medicine. 2010 Jan-Jun; 32 (1): 1-2.

11. Elhwuegi A. S. Central monoamines and their role in major depression. Journal of Neuropsychopharmacology. May 2004; 28 (3): 435-51

12. Victor I. Reus. Mental disorders. In: Stephen L. Hauser(ed). Harrison's Neurology in Clinical Medicine, 3rd Edition. New York: Mc Graw Hill Education; 2013.p. 720-741.

13. Wayane $C$ Drevets. Neuroimaging studies of mental disorders. In: Denis schamay, Eric Nestle, Benjamin S bunney(eds.) Neurobiology of mental illness. New York: Oxford university press; 1999. p.395-396. 